Review

\title{
Patterns in the collaboration of practitioners and researchers in the use of electrical stimulation to treat stroke patients: a literature review
}

\author{
Shuhei Fujimoto, PT, MHSc ${ }^{1,2)^{*}}$, Noriko Kon, OT ${ }^{1,3)}$, NaOki Takashi, OT ${ }^{1)}$, \\ Yohei Otaka, $\mathrm{MD}^{2,4)}$, Takeo Nakayama, $\mathrm{MD}, \mathrm{PhD}^{1)}$ \\ 1) Kyoto University Graduate School of Medicine: Yoshidakonoemachi, Sakyo-ku, Kyoto \\ 606-8317, Japan \\ 2) Tokyo Bay Rehabilitation Hospital, Japan \\ 3) Kawakita Rehabilitation Hospital, Japan \\ 4) Keio University School of Medicine, Japan
}

\begin{abstract}
Purpose] The purpose of this study was to investigate the degree of collaboration between practitioners and researchers through research papers related to the implementation of electrical stimulation (ES) for stroke patients. [Methods] A systematic review of the literature was conducted to collect data from ES studies published before January 7, 2015. Five databases were searched for search terms related to stroke and ES. Inclusion criteria were original papers that reported on ES of the upper or lower limbs following stroke, after the exclusion of case reports, brain stimulation studies, and papers written in any languages other than English or Japanese. The outcome was the prevalence of research papers that included a practitioner as an author, that included a practitioner as an author or in the acknowledgements, and in which the practitioner was the first author. [Results] Based on the selection criteria, 165 papers were included in the final analysis. The prevalence of papers in which a practitioner was included as an author was 39\%. The prevalence of papers in which a practitioner was included as an author or in the acknowledgements was $50 \%$. A practitioner was the first author of $34 \%$ of the papers. [Conclusion] Collaboration on research papers related to ES for stroke patients is limited.
\end{abstract}

Key words: Evidence practice gap, Therapeutic electrical stimulations (TES), Time-series analysis

(This article was submitted Apr. 21, 2015, and was accepted May 25, 2015)

\section{INTRODUCTION}

Reducing the gap between research evidence and clinical practice, or the so-called evidence-practice gap, can lead to improved patient outcomes ${ }^{1)}$ and reductions in healthcare $\operatorname{costs}^{2}$. This gap is especially prominent in the field of stroke rehabilitation $^{3)}$. One example of the evidence-practice gap in stroke rehabilitation is the research finding that electrical stimulation therapy (ES) is effective in the treatment of upper and lower limb paralysis ${ }^{3)}$. Nevertheless, almost no rehabilitation therapists use ES in the clinical setting ${ }^{4)}$. This gap is very common despite ES implementation having been recommended by many clinical studies ${ }^{5,6)}$ and evidencebased clinical practice guidelines in several countries ${ }^{7-9)}$.

One proposed reason for the evidence-practice gap is the lack of a collaborative and symbiotic relationship between practitioners and researchers ${ }^{3)}$. However, we do not know

*Corresponding author. Shuhei Fujimoto (E-mail: shuheifujimototbr@gmail.com)

C2015 The Society of Physical Therapy Science. Published by IPEC Inc. This is an open-access article distributed under the terms of the Creative Commons Attribution Non-Commercial No Derivatives (by-ncnd) License $<$ http://creativecommons.org/licenses/by-nc-nd/3.0/>. how often practitioners and researchers collaborate in clinical studies of ES for stroke. If collaboration patterns are understood and improved, the evidence-practice gap may be reduced. Thus, the aim of this study was to investigate the degree of collaboration between practitioners and researchers through research papers related to the implementation of ES for stroke patients.

\section{SUBJECTS AND METHODS}

A systematic review of the literature published before January 7, 2015 was conducted to collect data from ES studies. The literature recorded in five databases (PubMed, Cochrane database, PEDro, OTSeeker, and Ichushi Web) was explored for search terms related to stroke and ES. Because of limited manpower and the difficulty in identifying papers that matched the purpose of our study, manuscripts were only included if the search terms appeared in the study title. The following search terms were used in this study: stroke*[ti] OR apoplexy[ti] OR cerebrovascular[ti] OR vascular[ti] OR accident*[ti] OR attack[ti] AND electrical[ti] AND stimulation*[ti]. Inclusion criteria were original papers that reported on ES for the upper or lower limbs following stroke, after the exclusion of case reports, opinions, systematic reviews, protocols, letters, brain stimulation studies, and 
Table 1. The prevalence of papers which a practitioner contributed to

\begin{tabular}{lccc}
\hline & $\begin{array}{c}\text { practitioner included } \\
\text { as an author }\end{array}$ & $\begin{array}{c}\text { practitioner included as an author } \\
\text { or in the acknowledgements }\end{array}$ & $\begin{array}{c}\text { practitioner listed } \\
\text { as the first author }\end{array}$ \\
\hline Prevalence & 0.39 & 0.50 & 0.34 \\
\hline
\end{tabular}

Table 2. The collaboration patterns over the past 6 years

\begin{tabular}{ccccccc}
\hline \multirow{2}{*}{ Prevalence } & \multicolumn{7}{c}{ Year } \\
\cline { 2 - 7 } & 2009 & 2010 & 2011 & 2012 & 2013 & 2014 \\
\hline A & 0.37 & 0.50 & 0.47 & 0.20 & 0.55 & 0.34 \\
B & 0.37 & 0.50 & 0.47 & 0.30 & 0.59 & 0.62 \\
C & 0.42 & 0.21 & 0.21 & 0.50 & 0.32 & 0.41 \\
\hline
\end{tabular}

A: The prevalence of papers in which a practitioner was included as an author

B: The prevalence of papers in which a practitioner was included as an author or in the acknowledgements section

C: The prevalence of papers in which a practitioner was listed as the first author

papers written in languages other than English or Japanese.

Two reviewers independently extracted data based on the criteria, and assessed the collaboration patterns between practitioners and researchers based on the following conditions. A practitioner was defined as a person who included a hospital as an affiliation, while a researcher was identified as an individual who only belonged to a research institution such as a university, college, or research center. In this study, a researcher was defined as a person whose affiliation in the author's list was for a university but who actually worked in a hospital at the university, because a decision cannot be made based on affiliation alone.

The primary outcome was the prevalence of research papers that included a practitioner as an author. Secondary outcomes were the prevalence of research papers that included a practitioner as an author or in the acknowledgements, and research papers in which the practitioner was the first author.

In the statistical analysis, the degree of collaboration was calculated for every year from 2009 to 2014, and a time series analysis was performed on the data. The time series analysis was done with JMP Pro11 (SAS institute Inc., Cary, North Carolina), and white noise was employed to determine the presence of a significant autocorrelation. Significance was accepted for values of $\mathrm{p}<0.05$.

\section{RESULTS}

Our literature review identified 489 papers, and our final analysis included 165 papers based on the selection criteria. The prevalence of papers in which a practitioner was included as an author was $38.8 \%(n=64)$, while the prevalence of papers in which a practitioner was included as an author or in the acknowledgements section was $49.7 \%(n=82$, Table 1$)$. A practitioner was listed as the first author in $33.9 \%(\mathrm{n}=56)$ of the papers. There were no significant autocorrelations in any of the years investigated. These results indicate that the degree of collaboration between practitioners and researchers was less than $50 \%$.

Data for each year indicated that the prevalence of papers in which a practitioner was included as an author, as an author or in the acknowledgements, and as the first author remained unchanged (Table 2). The time series analysis revealed that there was no significant autocorrelation $(\mathrm{p}=$ $0.62-0.99$ ). Therefore, the results indicate that there was no white noise obscuring collaboration patterns between practitioners and researchers, and that they have remained unchanged since 2009.

\section{DISCUSSION}

In this study, a limited degree of collaboration between practitioners and researchers was found in published studies employing ES for stroke patients despite the fact that study participants are generally recruited in hospitals. In the following discussion, two reasons are suggested for the limited cooperation between practitioners and researchers, and we argue the importance of collaboration.

First, only researchers decide which study themes are relevant. Moreover, researchers who have employed ES for stroke have reported clinically significant findings and are thus motivated to adopt ES. However, once these researchers leave the clinical field, their communication with practitioners is often limited. Second, most practitioners do not spend their free time participating in research activities. For example, our preliminary study found that, if given the opportunity, less than $50 \%$ of physical therapists would spend their free time participating in research activities.

Previous reports in other research fields have indicated that successful relationships between practitioners and researchers often lead to evidence-based practices and good patient treatment ${ }^{10-12}$. Thus, these issues were resolved, practitioners would more likely implement and facilitate evidence-based practices.

In conclusion, more collaboration between practitioners and researchers may facilitate the implementation of ES, which would help close the gap between research evidence and clinical practice. Furthermore, this collaboration would likely result in higher levels of recovery among patients with stroke. 


\section{REFERENCES}

1) Komajda M, Lapuerta P, Hermans N, et al.: Adherence to guidelines is predictor of outcome in chronic heart failure: the MAHLER survey. Eur Heart J, 2005, 26: 1653-1659. [Medline] [CrossRef]

2) Shapiro DW, Lasker RD, Bindman AB, et al.: Containing costs while improving quality of care: the role of profiling and practice guidelines. Annu Rev Public Health, 1993, 14: 219-241. [Medline] [CrossRef]

3) Walker MF, Fisher RJ, Korner-Bitensky N, et al.: From what we know to what we do: translating stroke rehabilitation research into practice. Int $J$ Stroke, 2013, 8: 11-17. [Medline] [CrossRef]

4) Takaoka K, Uguisu H, Okazaki D, et al.: The actual condition of the physi cal therapy seen from the position of the clinical spot-from the questionnaire for a physiotherapist-. Jpn J Electrophysical Agents, 2012, 19 $17-21$.

5) Kim Y, Yi CH, Lee YH, et al.: Immediate effects of dermatomal electrical stimulation on task-oriented movements in patients with chronic hemiplegia. J Phys Ther Sci, 2013, 25: 89-91. [CrossRef]

6) Kim MY, Kim JH, Lee JU, et al.: The effects of functional electrical stimulation on balance of stroke patients in the standing posture. J Phys Ther
Sci, 2012, 24: 77-81. [CrossRef]

7) Colorado Division of Workers' Compensation: Lower extremity injury medical treatment guidelines. Denver: Colorado Division of Workers' Compensation, 2009.

8) National Clinical Guideline Centre: Stroke rehabilitation. Long-term rehabilitation after stroke. London: National Institute for Health and Care Excellence (NICE), 2013.

9) Management of Stroke Rehabilitation Working Group: VA/DoD clinical practice guideline for the management of stroke rehabilitation. Washington DC: Veterans Health Administration, Department of Defense, 2010.

10) Carise D, Cornely W, Gurel O: A successful researcher-practitioner collaboration in substance abuse treatment. J Subst Abuse Treat, 2002, 23 . 157-162. [Medline] [CrossRef]

11) Özdemir M, Giannotta F: Improving dissemination of evidence-based programs through researcher-practitioner collaboration. New Dir Youth Dev, 2014, 2014: 107-116, 13-14. [Medline] [CrossRef]

12) Magin PJ, Marshall MJ, Goode SM, et al.: How generalisable are results of studies conducted in practice-based research networks? A cross-sectional study of general practitioner demographics in two New South Wales networks. Med J Aust, 2011, 195: 210-213. [Medline] 